\title{
Psychoanalytic Concepts Of Violence And Aggression
}

\author{
Svenja Taubner, \\ University of Heidelberg, Germany \\ Sven Rabung, \\ University of Klagenfurt, Austria \\ Anthony Bateman, \\ UCL, United Kingdom \\ and \\ Peter Fonagy, \\ UCL, United Kingdom
}


Psychoanalytic clinical theories focus on three different assumptions that overlap to a certain extent depending on individual history (OPD Task Force, 2008): Psychopathology (a) manifests itself as an expression of unconscious conflict between different wishes and needs as well as expectations from the social environment, (b) is an expression of an impairment of personality functioning, and (c) evolves in dysfunctional relationships. Bearing in mind biological protective and risk factors (e.g. Hill, 2002), mental disorders are mainly seen as manifestations of early problems arising from childhood experiences. Thus, psychoanalytic theories tend to deal with the question of how early experiences can have an impact on adult functioning. For example, Benjamin (2003) has stated that representations of past interactions get "copied" into present interactions by three different processes: identification (behaving like a significant other), recapitulation (behaving as being in control of the other), and introjection (treating the self the same way the other did). Psychoanalytic thinking aims to understand each patient individually, starting with the etiology of problems and progressing to the specific psychogenesis of symptoms, that is, how a person copes specifically with aversive experiences and current life situations. In that sense, any psychopathology is regarded as an adaptation to inner and attachment-related problems associated with impaired functioning or dynamic defenses against unbearable mental states. Later in life, these "solutions" may become rigid, may not fit well with the demands of current situations, and may cause suffering both for the individual and for others around him/her. This basic assumption leads to a quite unique stance in psychoanalytic theory, in which symptoms - even the most cruel or irrational behavior - are considered to be meaningful in terms of assuming a vital function of regulating the self or interpersonal relationships. The hidden (or, rather, not superficially obvious) meaning of symptoms can be understood in terms of the individual's personal history, unconscious conflict, or structural impairment incurred in the course of psychological adaptation to environmental demands which the individual aims to cope with within the limits of his/her constitutional capacities and social resources.

\section{PSYCHODYNAMIC UNDERSTANDING OF VIOLENCE}

Psychoanalytic theories underline that violence, defined as open aggression with the intent to physically harm or even kill others, is indeed within the expectable range of human behavior - and so evidently a human potential; however, since it is not ubiquitous, most theories regard hostile aggression as not inborn (Parens, 1991) and focus on the social and developmental context that actualizes the potential. Mostly psychoanalytic theories see (chronic) individual violence as a sign or symptom of failure of expectable developmental support, in other words, a developmental disorder (Fonagy, 2008).

From a psychoanalytic viewpoint, individual non-hostile aggression is regarded as one of the biological constants of the human condition and the source of our vitality and energy. Psychoanalysts consider aggression, in the purest original sense of the word, to be in the service of the survival of the individual and to support the fulfilment of biological needs (e.g. food, procreation) and linked secondary requirements for autonomy and exploration. Not generally accepted by all psychoanalysts, but a key component of many influential formulations, is the view of aggression as a reaction to frustration serving the function of self-assertion, dominance, and competition in groups (Lichtenberg, 1989, Parens, 1979, Winnicott, 1965). About 70\% of children show these forms of assertive aggression, with a peak in aggressiveness at the age of two years (Cote, Vaillancourt, LeBlanc, Nagin, \& Tremblay, 2006). This is followed by a steady decline in aggressiveness in the majority, which leads to the hypothesis that for most people interpersonal aggression is evolutionarily programmed to be "unlearned", and not learned in normal development, in the service of optimal adaptation to the cultural context (Fonagy, 2008). Assertive aggression, which can be observed even in newborns, is self-protective and shields the individual from an experience of vulnerability. It is (at least heuristically) distinguishable from physical hostile aggression or violence, which aims intentionally to 
harm. Intentional hostile aggression is based on an individual's ability to plan an action and capacity to empathize with somebody else and take the victim's perspective, which is probably fully possible only for humans from around the age of 4 years and is somewhat limited in anthropoid apes (Bischof-Köhler, 2011). (Note that "empathize" carries no valence and is not synonymous with "feeling for" or "being sympathetic" but rather simply reflects the capacity to imagine the impact of an act on another's mental state. ) Some psychoanalytic authors, including Freud (1930), have even argued that sadistic aggression - probably the cruelest variation of hostile aggression - is restricted to humans because it requires the perpetrator to elaborate an image of the victim's mental pain. At the same time, phantasies can set free destructive processes that turn minimal insults into massive humiliation by misinterpretation or inaccurate mentalizing that lays the ground for reactive hostile aggression (Thomä \& Kächele, 1985).

Interestingly, our ability to mentalize normally prevents us from intentionally hurting others because it is painful for an observer if conspecifics are in (emotional) distress (Blair, 1995). Expressions of anxiety and sadness are normally responded to by compassion as well as actions of comforting and caregiving. According to Blair (2005), inhibition of acting violently relies on a violence inhibition mechanism in which hurting others intentionally causes mental pain in the observer especially when the observer is the cause of the pain. In that sense, the performance of violent actions seems to be related to not experiencing the victim as a feeling and thinking person any more (Levinson \& Fonagy, 2004). Epidemiological and longitudinal studies have convincingly demonstrated the relationship between childhood maltreatment and disruptive disorders, including acts of violence ( Jaffee et al., 2005; Loeber, Burke, \& Lahey, 2002; Moffitt, Caspi, Harrington \& Milne, 2002). However, the mechanisms underlying the relationship - that is, how the experience of early maltreatment is transformed into a potential for violence against others or the self (i.e., selfmutilation) - is still poorly understood. McCrory and Viding (2015) suggest, in relation to maltreatment, that adaptation or altered calibration within a neurocognitive system will generate vulnerability where negative valence systems will invariably come to be affected. The challenge for researchers is the operationalization of what McCrory and Viding refer to as "latent vulnerability," the identification of tests of neurobehavioral function that reveal risk status in terms of a range of systems-level dimensional constructs, which in principle are independent of DSM diagnostic groupings. This, in essence, is what the conceptual framework for resilience research proposed by developmental psychopathology (Cicchetti, 2013; Fonagy, Steele, Steele, Higgitt, \& Target, 1994; Stein, Fonagy, Ferguson, \& Wisman, 2000) also aims to deliver.

Recent studies actually suggest a hierarchical organization of psychiatric disorders, with high correlations among internalizing and externalizing disorders pointing to common vulnerabilities probably underlying both (Caspi et al., 2014; Fonagy, Luyten, \& Allison, 2015; Lahey, Van Hulle, Singh, Waldman, \& Rathouz, 2011; Patalay et al., 2015). Here we argue that perhaps several developmental pathways implicated in aggressive and antisocial behavior (AAB) may involve temporary or enduring impairments in social cognition (Sharp, Fonagy, \& Goodyer, 2008), in particular capacity for social learning and the use of mental state awareness (mentalizing) to appropriately interpret social actions and moderate/regulate behavior. In Research Domain Criteria terms (Insel et al., 2010), we propose that difficulties with systems for social processes are key in major group(s) of individuals who currently receive this diagnosis. But paths to and from problems of social impairment define distinct courses of the disorder, with varying key points for effective intervention (McCrory \& Viding, 2015). We favor a view that, from an evolutionary and developmental perspective, some types of aggressive antisocial behavior problems can be seen as reflecting the unlearning of the use of normally evolutionarily protected social learning systems that function to facilitate intergenerational knowledge transmission and protect social collaborative processes from impulsive and aggressive actions. Impairments in other domains of functioning, such as in negative and positive valence 
systems and cognitive systems, interact with such unlearning, although they may also generate $A A B$ without implicating social processes in causation. This permits us to view $A A B$ as a specific adaptation of neurobiological systems and therefore is in itself not problematic. There needs to be a shift from seeing aggression and conduct problems as reflecting learned behavior (Bandura, 1986), to a problem of the "normal" unlearning of a natural fight/flight response. This is not at all a new idea, and has roots in 19th and early 20th century psychology (Freud, 1930; McDougall, 1920) that was perhaps intellectually similar to our times in prioritizing the biological underpinning of mental disorder. Yet, the study of the developmental psychopathology and neurobiology of social cognition in relation to aggression has thankfully advanced considerably from 19th century instinct theory, giving us a clearer view of the neurobehavioral processes involved. Drawing from extensive observation of children and clinical groups, psychoanalytic clinical hypotheses and conceptualizations may shed light on understanding the circumstances in which social learning fails from a psychoanalytic developmental point of view.

\section{PSYCHODYNAMICS AND ETIOLOGY OF VIOLENCE}

Some psychoanalytic conceptions have dealt with violence in the framework of psychiatric diagnoses, such as antisocial personality disorder (ASPD), conduct disorder, narcissistic personality disorder, etc. (Meloy, 2001). However, individuals with these diagnoses do not necessarily behave violently, and hostile aggression can occur with numerous other mental disorders, notably psychosis or borderline personality disorder (BPD). Thus, in this chapter we will follow the idea that violence is not tied to a specific diagnosis, and will therefore consider it as a symptom on its own with quite diverse clinical contexts, meanings, and etiologies. At the same time, violence may have a common phenomenological core, and we will argue this to include an unbearable affective state or the perceived danger of self-fragmentation. The violent act in that sense is regarded as a way of coping with unbearable affect and to protect the individual from the fragmentation of the self. Furthermore, the specific act can have symbolic meaning that can be understood in the light of the individual's history, affects, motives and defense mechanisms (Gilligan, 2011).

There are at least two exceptions to this kind of psychodynamic construction concerning violence. One is violence that has been legitimized by society to ensure a state's security or peace. The second is violence associated with criminal intent and has been described as "psychopathic violence" that is committed "in cold blood" to achieve a certain goal, or even for the perpetrator to experience pleasure by hurting others (Holt, Meloy, \& Strack, 1999), and is commonly developmentally antedated by callous-unemotional (CU) conduct problems in childhood. The former is usually not seen as problematic and the latter is true for only a relatively small percentage of violent offenders. There is good evidence that a subgroup of children and adolescents with conduct disorder (15-45\%) (Rowe et al., 2010) is characterized by high CU traits, usually referring to a lack of empathy and guilt in combination with poverty of emotional expression (Kimonis, Frick, Munoz, \& Aucoin, 2008). Although the presence of high CU traits in conduct disorder appears to signal a more severe, stable, and increasingly aggressive course, with distinct emotional, cognitive, temperamental, biological, and social risk factors (Frick, Ray, Thornton, \& Kahn, 2014; Longman, Hawes, \& Kohlhoff, 2015; Waller et al., 2015) in etiological models of AAB conduct disorder, we need to remain aware that it is also true that not all those with high CU traits have conduct disorder (Kumsta, SonugaBarke, \& Rutter, 2012; Moran, Ford, Butler, \& Goodman, 2008; Musser, Galloway-Long, Frick, \& Nigg, 2013). Longitudinal studies suggest that CU traits may be forerunners of psychopathic features in adults (Frick, Cornell, Barry, Bodin, \& Dane, 2003; Lynam \& Gudonis, 2005) even when the number and onset of conduct problems and youth symptoms of attention-deficit/hyperactivity disorder are controlled for (McMahon, Witkiewitz, Kotler, \& Conduct Problems Prevention Research Group, 2010). Lynam, Caspi, Moffitt, Loeber, and Stouthamer-Loeber (2007) report that children who at age 
13 were in the upper $10 \%$ of CU traits were over three times more likely to show elevations in an adult measure of psychopathy.

So far there is no specific psychodynamic treatment to address psychopathy, and this group has been widely regarded as untreatable with psychotherapeutic methods only (Kernberg, 2014). Thus, in this chapter we will concentrate on the understanding and treatment of "hot-blooded" violence. However, it seems that a continuum between different forms of violence is far more likely than conceptualizing them as distinct groups of individuals (Edens, Marcus, \& Vaughn, 2011), which may help to target psychopathy with psychotherapeutic efforts in the future, especially relatively early in development. Although reviews generally show high CU trait children to be less responsive to treatment (Dadds, Cauchi, Wimalaweera, Hawes, \& Brennan, 2012; Manders, Dekovic, Asscher, van der Laan, \& Prins, 2013; Masi et al., 2013), some reviewers are not convinced that high CU individuals change less in treatment. Their poorer outcome may simply reflect their poor premorbid functioning (Waller, Gardner, \& Hyde, 2013). Nevertheless, an understanding of this disorder as a specific problem associated with the inaccessibility of processes underpinning social learning calls for a qualitatively different approach to address this deficit.

"Hot-blooded" violence seems to be particularly triggered by feelings of shame, anxiety, envy, and hatred. In those cases, when violent acts serve to regulate these emotional states, the offender is relieved afterwards but reports a certain kind of dissociative, sometimes dream-like experience, during the violent act and an impaired sense of self-agency, which hints at the understanding of this type of violence as perhaps closely related to trauma experiences and trauma triggers (Taubner, 2008; Yakeley \& Adshead, 2013). The mechanism of how this works can be explained psychoanalytically as quite a concrete form of projective identification which forces somebody else - the victim and society in general - to feel the emotional states that the offender cannot contain (Lackinger, 2008).

\section{Hatred and envy}

Two powerful psychoanalytic models root violence in the individual's struggle with excessive hatred and envy born of adversity that generates overwhelming affect and simultaneously impairs the development of mental structures of morality necessary to deal with these. Kernberg (1989, 2004,2014 ) has developed a complex understanding of antisocial behavior including violent acts, linking it with his sophisticated model of personality organization, and focuses on degrees of superego pathology. In contrast to Kernberg, Rauchfleisch (2008b) argues that antisocial individuals do have a superego; however, dissociated parts alternate, ranging from childlike omnipotent phantasies to sadistic persecution of the self. Both authors focus on the relation between pathological narcissism and the experience of extreme rage, hatred, and envy in the face of others who seem to have everything that the antisocial personality wishes for.

Pathological narcissism is regarded as a personality organization that evolves in the face of very neglectful and abusive early attachment experiences. Individuals with this narcissistic syndrome suffer from severe feelings of inadequacy alternating with feelings of grandiosity. The grandiose self is centered on three building blocks (Rauchfleisch, 2008a): 1) the belief that one is special; 2) ideas of achieving power, wealth, omnipotence, omniscience, etc.; and 3) phantasies of unlimited love, caregiving, and unlimited supply from others. This fantasy refuge is often the opposite of the individual's real-life experience of pain, neglect, rejection, and pervasive lack of affection. Antisocial adults with a grandiose self, report pseudo-logically about their current life and tend to reframe their miserable settings in a grandiose manner. At the same time they feel a chronic emptiness as well as an absence of fulfillment and meaning in their lives. 
Because of their substantial early traumatization and repeated experience of rejection, individuals with this kind of developmental history remain extremely greedy for concrete physical gratification, using and abusing food, alcohol, drugs, sex, and any kind of material fulfillment. Interpersonal relationships become instrumental (used for functional gain), with the individual having a tendency to exploit and manipulate others. As soon as relationships cease to fulfill the individual's expansive needs, intensive hatred is generated, which can, on occasion, lead to violence (Rauchfleisch, 1999).

The origin of such a state of affairs is linked to early maltreatment that leaves a developing self in an unsustainable and unbearable state of helplessness. From Kernberg's (1989) point of view, one way of surviving this is by identifying with the aggressor and developing a generalized expectation that one lives in a world of predators and prey. Identification with the aggressor leads to the conviction that nothing good or dependable can be expected from others. To be good means to be weak and to become potential prey. This is accompanied by chronic hatred and envy of others who refuse to blindly serve and thus potentially threaten the fragile self, or who seem to be living in an inner world that is not tormented by violence. Furthermore, the projection of hatred in most relationships fosters a paranoid expectation that one will be harmed and exploited by others. This, of course, leads to a constant feeling of being in danger, and generates an understandable readiness to protect the self from becoming the victim again. The motto of such individuals can be summarized as: "Rather be a wolf among wolves and sheep than a sheep among wolves". As Kernberg puts it, sadistic control of others is seen as the only solution against suffering again.

\section{Shame}

An alternative influential psychoanalytic theory of violence, advanced by James Gilligan $(2000,2011)$, rooted violence in the acquired vulnerability of the violent person to the experience of shame. Gilligan developed his model as a forensic psychiatrist working with violent men, primarily murderers, in high-security prisons. He proposed that studying the extreme end of the continuum of violence will help to understand the mechanisms behind violence as a behavioral problem and may also offer a frame for reducing the risk of future violence.

From Gilligan's point of view, violence does not imply immorality, goes along with the subjective experience of justice, and is always triggered by intense feelings of shame. He believes that while, normally, words are used as symbolic representations of thoughts, phantasies, and feelings, that help to regulate the self, violent offenders are limited in their capacity to express themselves in words, and act out unbearable self-states. Here, bodily actions are believed to be used as a form of proto-language to express and communicate emotions and intentions. Thus, actions, even violent ones, can be interpreted, providing a route to understand the subjective experiences ("reasons") behind an apparently meaningless violent act.

Gilligan develops his etiologic ideas based on the observation that these extremely violent men report having no feelings at all and experience themselves as "living dead". This subjective experience has been linked to extremely severe forms of childhood maltreatment and early close-todeath experiences that lead to a "soul murder" (Shengold, 1979) in a body that is still biologically functioning. Gilligan describes several basic motives to hurt others fatally when experiencing the self as dead. One is close to Kernberg's focus on envy, insofar that he suggests that violent men may not be able to bear the idea that others are still feeling alive, manifesting autonomy and agency, when the person's own experience of selfhood has perished. In a slightly different vein, some extreme forms of violence have been reported to be cruel experiments by the perpetrator to find out whether killing another person will make them feel anything again. However, hurting others normally does 
not restore a "living soul", and thus extreme forms of self-mutilation (common in prison settings; Binks et al., 2006) occur to create feelings, for it is better to feel pain than nothing at all.

Central to Gilligan's thesis are the numerous cases (described in his monograph; Gilligan, 2001) in which seemingly small insults or even the fantasy of being humiliated appear to lead to extreme violence. One evocative case depicted a man who murdered a former classmate when she was giving him a ride. The murderer acted upon the fear that she had seen and would tell others that he was not able to repair his own car (Gilligan, 2011). Thus, for Gilligan, murder is the symbolic representation of a paranoid thought. During paranoia, the ability to differentiate between feelings and facts becomes overwhelmed by shame or the delusion of shame. In the eye of the murderer, violence is self-defense not to be shamed again and to be protected from losing his mind.

The inability to experience, symbolize (other than in action), and contain shame can be seen as rooted in the processing of physical and psychological violence towards children. Gilligan describes how violence in early attachment relationships is the ultimate communication of the absence of love. A developing self that is constantly shamed, humiliated, and hurt instead of loved becomes numb. No healthy pride (a sense of self-love and self-esteem) can emerge. Later, this person cannot take the risk of loving others, as the risk of being rejected again carries the risk of annihilation. This inability to love leads to a joyless life with a hypersensitivity to insult. Whenever another person is experienced as potentially shaming, the individual "drowns in an ocean of hatred" (Gilligan 2000). To prevent this, the person becomes committed to the fantasy to be never shamed again.

In sum, three preconditions are related to the act of violence. First, shame is triggered by an actual or perceived action of another person with such intensity that the individual is unable to contain the feeling. Second, there is no cultural or personally valued goal that is placed at risk through violent action. And third, there is an absence of love, guilt, or fear for the self that would mitigate the risk of violence (Gilligan 2000). Consistent with a psychoanalytic point of view, societal punishment is expected to have a negative effect on all three of the above preconditions (amplifying shame, reducing cultural and personal social investment, weakening bonds, reducing guilt, and lessening fear of retribution) and, in most instances, likely serves to facilitate violence instead of preventing it.

\section{Anxiety}

The third approach to violence that is currently relevant for the psychodynamic treatment of violence is the mentalization-based approach, which forms a bridge between the psychoanalytic model and attachment theory as well as developmental sciences (Fonagy, Gergely, Jurist \& Target, 2002). Within this framework, the limitation and breakdown of the offender's mental capacity to experience the victim as a feeling and thinking person is central to the understanding of the violent act alongside the high risk of misinterpretation of social cues and a limited capacity for self-control.

Mentalizing is the ability to understand one's own behavior and the behavior of others in terms of mental states. It is an essential human capacity that underpins social collaboration and, probably to assure this function, it is capable of inhibiting violent aggressive social action (Fonagy, 2004). Mentalizing develops during childhood, from teleological to intentional and finally to mentalizing understanding of self and others, which means robust awareness of the representational nature of mental states (Frith \& Frith, 2012). A teleological understanding of behavior is solely based on observable outcomes, while an intentional understanding implies the presumption of motives in terms of feelings and beliefs. Violent individuals frequently experience a merely teleological mode of understanding that is strictly limited to detecting what happens in the physical world - that is, what is the outcome of an action, regardless of its impact on subjective experience (of either the self or the other). Fonagy and colleagues consider mentalizing, in a similar fashion to language, to be a 
biologically programmed developmental achievement, which is crucially dependent on the family context. Secure attachment relationships promote rapid acquisition of mentalizing (Arnott \& Meins, 2007; Fonagy \& Target, 1997). By contrast, mentalizing can be severely impaired when early relationships become brutalized (Cicchetti, Rogosch, Maughan, Toth, \& Bruce, 2003; Ensink, Berthelot, Bernazzani, Normandin, \& Fonagy, 2014; Ensink et al., 2015; Pears \& Fisher, 2005).

The impact of the quality of parenting on behavioral outcomes may be mediated through the mechanisms of affect regulation and selective attention. For example, Derryberry and Rothbart (1997) assume that children who have not experienced support and calming from their early caregivers in anxiety-provoking situations are likely to develop avoiding strategies to hide or deny such situations instead of experiencing inner and social coping possibilities. They suggest two possible long-term consequences from anxiety-avoiding strategies: (a) such children will be less attentive to anxiety-provoking information and will not be able to handle difficult social situations effectively and appropriately. Instead, they develop maladaptive coping strategies based on compulsion; (b) the child will not benefit from the positive consequences of felt anxiety in the sense of promoting affect regulation, impulse control, empathy, and anxiety consciousness.

Fonagy and colleagues (2002) have proposed a similar model in conceptualizing inhibited mentalization as an adaptation to the brutalization of an attachment relationship (Adshead, Fonagy, \& Sarkar, 2007; Fonagy, 1999; Fonagy, 2003). Inhibition of mentalizing serves as a protection because children no longer need to think about a perpetrator's frankly malevolent motives when they are simultaneously vulnerable to or existentially depending on the same individual. If others' actions are not interpreted in terms of their motives, wishes, emotions and beliefs, the understanding becomes "concrete"; that is, it is restricted to an understanding in terms of physical or observable reality. If mentalizing is inhibited, the social environment is no longer interpreted from the "intentional stance," but from a "physical stance" (Dennett, 1987). In this case, an angry voice can be perceived as being only loud, and a threatening gesticulation is seen only as a raised arm (Hill, Fonagy, Lancaster, \& Broyden, 2007). This specific non-intentional approach to anxiety-provoking situations was demonstrated for children with externalizing disorders (Hill et al., 2007; Hill, Murray, Leidecker, \& Sharp, 2008). There is accumulating evidence of substantial mentalizing problems in young people and adults with a combination of histories of maltreatment and of severe interpersonal aggression (Chiesa \& Fonagy, 2014; Elsegood \& Duff, 2010; Romero-Martinez, Lila, Catala-Minana, Williams, \& Moya-Albiol, 2013). Antisocial behavior has been consistently shown to be associated with observed deficits in mentalizing across a number of measures (Newbury-Helps, Feigenbaum, \& Fonagy, in press), especially in violent subgroups (Levinson \& Fonagy, 2004; McGauley, Ferris, MarinAvellan, \& Fonagy, 2013).

In line with these findings, Bateman and Fonagy (2012) propose a probable mediation between childhood maltreatment and externalizing problems through inadequate interpersonal understanding as well as limited behavioral flexibility in response to demands from the environment. It is argued that a child who is maltreated by his/her own caregivers cannot experience being treated as a feeling and thinking being because his or her experience is of being treated like a physical object. Being recognized as a feeling and thinking human being is a necessary prerequisite to experiencing oneself and others as thinking and feeling beings, and to be able fully to mentalize others. Thus, individuals who were treated like physical objects are prone to treat themselves and others without reliably attributing intentionality to self or others, especially when intense emotions arise that cannot be contained in a mentalizing way but only by using one's own body or violent action.

Using structural equation modeling, the potential for violence in adolescence (defined as aggression and diagnosis of conduct disorder) was predicted by childhood maltreatment (neglect, antipathy, and physical abuse); however, this relationship was partially mediated by the adolescent's 
reflective functioning (used as a measure of mentalizing; Taubner, Zimmermann, Ramberg \& Schröder, submitted). Similar findings were reported by Ensink and colleagues (Ensink et al., 2015) with samples of sexually abused young people.

\section{DISCUSSION}

In this chapter we aimed to illustrate the rich conceptualization of violence from psychoanalytic perspectives that derived from a clinical understanding of the personality psychopathology behind violent acts. Although the theories emphasize different triggers or central emotions - hatred, envy, shame, and anxiety - the main message of all the theories is that chronic violence can be regarded as an expression of the individual's inability to symbolize or mentalize feelings and thoughts. An overarching aspect of the psychoanalytic perspective presumes the need to manage unbearable emotional experiences and beliefs through action rather than mentalizing. This suggests that preventing future violence requires attending to the meaning of the violent action and re-establishing a symbolizing/mentalizing function in the patient as well as preventing early maltreatment. 


\section{References}

Adshead, G., Fonagy, P., \& Sarkar, S. P. (2007). Violence and gun crime. BMJ, 335, 837. doi: 10.1136/bmj.39365.683877.BE

Arnott, B., \& Meins, E. (2007). Links among antenatal attachment representations, postnatal mindmindedness, and infant attachment security: A preliminary study of mothers and fathers. Bulletin of the Menninger Clinic, 71, 132-149. doi: 10.1521/bumc.2007.71.2.132

Bandura, A. (1986). Social learning theory. Englewood Cliffs, NJ: Prentice-Hall.

Bateman, A. W., \& Fonagy, P. (Eds.). (2012). Handbook of mentalizing in mental health practice. Washington, DC: American Psychiatric Publishing.

Benjamin, L. S. (2003). Interpersonal diagnosis and treatment of personality disorders. Diagnosis and treatment of mental disorders (2nd ed.). New York, NY: Guilford Press.

Bischof-Köhler, D. (2011). Soziale Entwicklung in Kindheit und Jugend: Bindung, Empathie, Theory of Mind (1st edn.). Stuttgart, Germany: Kohlhammer. [Social development in childhood and youth]

Blair, R. (1995). A cognitive developmental approach to morality: Investigating the psychopath. Cognition, 57, 1-29.

Blair, R. J. R. (2005). Responding to the emotions of others. Dissociating forms of empathy through the study of typical and psychiatric populations. Consciousness and Cognition, 14(4), 698-718. doi: 10.1016/j.concog.2005.06.004

Caspi, A., Houts, R. M., Belsky, D. W., Goldman-Mellor, S. J., Harrington, H., Israel, S., . . Moffitt, T. E. (2014). The p factor: One general psychopathology factor in the structure of psychiatric disorders? Clinical Psychological Science, 2, 119-137. doi: 10.1177/2167702613497473

Chiesa, M., \& Fonagy, P. (2014). Reflective function as a mediator between childhood adversity, personality disorder and symptom distress. Personality and Mental Health, 8, 52-66. doi: 10.1002/pmh.1245

Cicchetti, D., Rogosch, F. A., Maughan, A., Toth, S. L., \& Bruce, J. (2003). False belief understanding in maltreated children. Development and Psychopathology, 15, 1067-1091. doi: 10.1017.S0954579403000440

Cicchetti, D. (2013). Annual research review: Resilient functioning in maltreated children-past, present, and future perspectives. Journal of Child Psychology and Psychiatry, 54, 402-422. doi: 10.1111/j.1469-7610.2012.02608.x

Cote, S. M., Vaillancourt, T., LeBlanc, J. C., Nagin, D. S., \& Tremblay, R. E. (2006). The development of physical aggression from toddlerhood to pre-adolescence: A nation wide longitudinal study of Canadian children. Journal of Abnormal Child Psychology, 34, 71-85. doi: 10.1007/s10802-0059001-z

Dadds, M. R., Cauchi, A. J., Wimalaweera, S., Hawes, D. J., \& Brennan, J. (2012). Outcomes, moderators, and mediators of empathic-emotion recognition training for complex conduct problems in childhood. Psychiatry Research, 199, 201-207. doi: 10.1016/j.psychres.2012.04.033

Derryberry, D., \& Rothbart, M. K. (1997). Reactive and effortful processes in the organization of temperament. Development and Psychopathology, 9(4), 633-652. doi: $10.1017 /$ S0954579497001375

Dennett, D. C. (1987). The intentional stance. Cambridge, MA: MIT Press.

Edens, J. F., Marcus, D. K., \& Vaughn, M. G. (2011). Exploring the taxometric status of psychopathy among youthful offenders: Is there a juvenile psychopath taxon? Law and Human Behavior, 35(1), $13-24$.

Elsegood, K. J., \& Duff, S. C. (2010). Theory of mind in men who have sexually offended against children: A U.K. comparison study between child sex offenders and nonoffender controls. Sexual Abuse, 22, 112-131. doi: 10.1177/1079063209359926 
Ensink, K., Berthelot, N., Bernazzani, O., Normandin, L., \& Fonagy, P. (2014). Another step closer to measuring the ghosts in the nursery: Preliminary validation of the Trauma Reflective Functioning Scale. Frontiers in Psychology, 5, 1471. doi: 10.3389/fpsyg.2014.01471

Ensink, K., Normandin, L., Target, M., Fonagy, P., Sabourin, S., \& Berthelot, N. (2015). Mentalization in children and mothers in the context of trauma: An initial study of the validity of the Child Reflective Functioning Scale. British Journal of Developmental Psychology, 33, 203-217. doi: 10.1111/bjdp.12074

Fonagy, P., Steele, M., Steele, H., Higgitt, A., \& Target, M. (1994). The Emanuel Miller Memorial Lecture 1992. The theory and practice of resilience. Journal of Child Psychology and Psychiatry, 35, 231-257.

Fonagy, P., \& Target, M. (1997). Attachment and reflective function: Their role in self-organization. Development and Psychopathology, 9, 679-700.

Fonagy, P. (1999). Male perpetrators of violence against women: An attachment theory perspective. Journal of Applied Psychoanalytic Studies, 1, 7-27.

Fonagy, P., Gergely, G., Jurist, E. L., \& Target, M. (2002). Affect regulation, mentalization, and the development of the self. London, UK: Karnac Books.

Fonagy, P. (2003). Towards a developmental understanding of violence. British Journal of Psychiatry, 183, 190-192.

Fonagy, P. (2004). Early life trauma and the psychogenesis and prevention of violence. Annals of the New York Academy of Sciences, 1036, 1-20.

Fonagy, P. (2008). Persönlichkeitsstörung und Gewalt. Ein psychoanalytisch-bindungstheoretischer Ansatz. In F. Lackinger \& W. Berner (Eds.), Psychodynamische Psychotherapie bei Delinquenz. Praxis der übertragungsfokussierten Psychotherapie (pp. 326-365). Stuttgart, Germany: Schattauer. [Personality disorder and violence. An approach from psychoanalytic and attachment theory]

Fonagy, P., Luyten, P., \& Allison, E. (2015). Epistemic petrification and the restoration of epistemic trust: A new conceptualization of borderline personality disorder and its psychosocial treatment. Journal of Personality Disorders, 29, 575-609. doi: 10.1521/pedi.2015.29.5.575

Freud, S. (1930). Civilization and its discontents. In J. Strachey (Ed.), The standard edition of the complete psychological works of Sigmund Freud (Vol. 21, pp. 57-146). London, UK: Hogarth Press, 1961.

Frith, C. D., \& Frith, U. (2012). Mechanisms of social cognition. Annual Review of Psychology, 63, 287313. doi: 10.1146/annurev-psych-120710-100449

Gilligan, J. (2000). Violence: Reflections on our deadliest epidemic. Forensic focus: Vol. 18. London, UK/Philadelphia, PA: Jessica Kingsley.

Gilligan, J. (2011). The interpretation of violence. In P. Williams (Ed.), Psychoanalytic ideas series. Aggression. From fantasy to action (pp. 67-94). London, UK: Karnac Books.

Hill, J. (2002). Biological, psychological and social processes in the conduct disorders. Journal of Child Psychology and Psychiatry, 43(1), 133-164.

Hill, J., Fonagy, P., Lancaster, G., \& Broyden, N. (2007). Aggression and intentionality in narrative responses to conflict and distress story stems. An investigation of boys with disruptive behaviour problems. Attachment and Human Development, 9(3), 223-237. doi:

10.1080/14616730701453861

Hill, J., Murray, L., Leidecker, V., \& Sharp, H. (2008). The dynamics of threat, fear and intentionality in the conduct disorders. Longitudinal findings in the children of women with post-natal depression. Philosophical Transactions of the Royal Society of London. Series B. Biological Sciences, 363(1503), 2529-2541. doi: 10.1098/rstb.2008.0036

Holt, S. E., Meloy, J. R., \& Strack, S. (1999). Sadism and psychopathy in violent and sexually violent offenders. Journal of the American Academy of Psychiatry and the Law, 27(1), 23-32. 
Insel, T., Cuthbert, B., Garvey, M., Heinssen, R., Pine, D. S., Quinn, K., ... Wang, P. (2010). Research domain criteria (RDoC): Toward a new classification framework for research on mental disorders. American Journal of Psychiatry, 167, 748-751. doi: 10.1176/appi.ajp.2010.09091379

Jaffee, S. R., Caspi, A., Moffitt, T. E., Dodge, K. A., Rutter, M., Taylor, A., \& Tully, L.A. (2005). Nature X nurture: Genetic vulnerabilities interact with physical maltreatment to promote conduct problems. Development and Psychopathology, 17(1), 67-84.

Kernberg, O. F. (1989). The narcissistic personality disorder and the differential diagnosis of antisocial behavior. Psychiatric Clinics of North America, 12(3), 553-570.

Kernberg, O. F. (2004). Aggressivity, narcissism, and self-destructiveness in the psychotherapeutic relationship: New developments in the psychopathology and psychotherapy of severe personality disorders. New Haven, CT/London, UK: Yale University Press.

Kernberg, O. F. (2014). An overview of the treatment of severe narcissistic pathology. International Journal of Psychoanalysis, 95(5), 865-888. doi: 10.1111/1745-8315.12204

Lackinger, F. (2008). Psychodynamische Strukturdiagnostik und Deliktanalyse bei persönlichkeitsgestörten Delinquenten. In F. Lackinger \& W. Berner (Eds.), Psychodynamische Psychotherapie bei Delinquenz. Praxis der übertragungsfokussierten Psychotherapie (pp. 3-37). Stuttgart, Germany: Schattauer. [Psychodynamic structural diagnosis and delict analysis with personality disordered delinquents]

Lahey, B. B., Van Hulle, C. A., Singh, A. L., Waldman, I. D., \& Rathouz, P. J. (2011). Higher-order genetic and environmental structure of prevalent forms of child and adolescent psychopathology. Archives of General Psychiatry, 68, 181-189. doi: 10.1001/archgenpsychiatry.2010.192

Levinson, A., \& Fonagy, P. (2004). Offending and attachment: The relationship between interpersonal awareness and offending in a prison population with psychiatric disorder. Canadian Journal of Psychoanalysis, 12, 225-251.

Lichtenberg, J. (1989). Psychoanalysis and motivation. Hillsdale, NJ: Analytic Press.

Loeber, R., Burke, J., \& Lahey, B. (2002). What are the adolescent antecedents to antisocial personality disorder? Criminal Behavior and Mental Health, 12, 24-36.

Newbury-Helps, J., Feigenbaum, J., \& Fonagy, P. (in press). Offenders with antisocial personality disorder display more impairments in mentalizing. Journal of Personality Disorders.

Manders, W. A., Dekovic, M., Asscher, J. J., van der Laan, P. H., \& Prins, P. J. (2013). Psychopathy as predictor and moderator of multisystemic therapy outcomes among adolescents treated for antisocial behavior. Journal of Abnormal Child Psychology, 41, 1121-1132. doi: 10.1007/s10802013-9749-5

Masi, G., Muratori, P., Manfredi, A., Lenzi, F., Polidori, L., Ruglioni, L., ... Milone, A. (2013). Response to treatments in youth with disruptive behavior disorders. Comprehensive Psychiatry, 54, 10091015. doi: 10.1016/j.comppsych.2013.04.007

McCrory, E. J., \& Viding, E. (2015). The theory of latent vulnerability: Reconceptualizing the link between childhood maltreatment and psychiatric disorder. Development and Psychopathology, 27, 493-505. doi: 10.1017/S0954579415000115

McDougall, W. (1920). The group mind: A sketch of the principles of collective psychology. New York, NY: Putnam.

Meloy, J. R. (2001). Introduction to section I. In J. R. Meloy (Ed.), The mark of Cain. Psychoanalytic insight and the psychopath (pp. 3-23). Hillsdale, NJ: Analytic Press.

Moffitt, T. E., Caspi, A., Harrington, H., \& Milne, B. (2002). Males on the life-course-persistent and adolescence-limited antisocial pathways: Follow-up at age 26 years. Development and Psychopathology, 14, 179-207.

OPD Task Force (2008). Operationalized psychodynamic diagnostics OPD-2: Manual of diagnosis and treatment planning. Cambridge, MA/Toronto, Canada: Hogrefe. 
Patalay, P., Fonagy, P., Deighton, J., Belsky, J., Vostanis, P., \& Wolpert, M. (2015). A general psychopathology factor in early adolescence. British Journal of Psychiatry, 207, 15-22. doi: 10.1192/bjp.bp.114.149591

Parens, H. (1979). The development of aggression in early childhood. New York, NY: Jason Aronson.

Parens, H. (1991). A view of the development of hostility in early life. Journal of the American Psychoanalytic Association, 39, 75-108.

Pears, K. C., \& Fisher, P. A. (2005). Emotion understanding and theory of mind among maltreated children in foster care. Development and Psychopathology, 17, 47-65. doi: $10.1017 /$ S0954579405050030

Rauchfleisch, U. (1999). Außenseiter der Gesellschaft: Psychodynamik und Möglichkeiten zur Psychotherapie Straffälliger. Göttingen, Germany: Vandenhoeck \& Ruprecht. [Outside of society: Psychodynamics and psychotherapeutic potentials for criminals]

Rauchfleisch, U. (2008a). Narzisstische Persönlichkeitsstörungen bei dissozialen Patienten. In F. Lackinger \& W. Berner (Eds.), Psychodynamische Psychotherapie bei Delinquenz. Praxis der übertragungsfokussierten Psychotherapie (pp. 453-464). Stuttgart, Germany: Schattauer. [Narcissistic personality disorder with dissocial patients]

Rauchfleisch, U. (2008b). Begleitung und Therapie straffälliger Menschen (2nd edn.). Göttingen, Germany: Vandenhoeck \& Ruprecht. [Supervision and therapy for criminal patients]

Romero-Martinez, A., Lila, M., Catala-Minana, A., Williams, R. K., \& Moya-Albiol, L. (2013). The contribution of childhood parental rejection and early androgen exposure to impairments in socio-cognitive skills in intimate partner violence perpetrators with high alcohol consumption. International Journal of Environmental Research and Public Health, 10, 3753-3770. doi: 10.3390/ijerph10083753

Sharp, C., Fonagy, P., \& Goodyer, I. (Eds.). (2008). Social cognition and developmental psychopathology. Oxford, UK: Oxford University Press.

Shengold, L. (1979). Child abuse and deprivation: Soul murder. Journal of the American Psychoanalytic Association, 27, 533-560.

Stein, H., Fonagy, P., Ferguson, K. S., \& Wisman, M. (2000). Lives through time: An ideographic approach to the study of resilience. Bulletin of the Menninger Clinic, 64, 281-305.

Taubner, S. (2008). Einsicht in Gewalt: Reflexive Kompetenz adoleszenter Straftäter beim Täter-OpferAusgleich. Giessen, Germany: Psychosozial-Verlag [Insight into violence: Reflective Functioning of adolescent offender in victim-offender-mediation]

Taubner, S., Zimmermann L., Ramberg, A. \& Schröder, P. (2015). Do mentalization and attachment mediate the relation between childhood maltreatment and adolescent potential for violence? Psychopathology. Manuscript submitted for publication.

Thomä, H. \& Kächele, H. (1985). Lehrbuch der psychoanalytischen Theorie. Heidelberg, Germany: Springer. [Handbook of psychoanalytic theory]

Waller, R., Gardner, F., \& Hyde, L. W. (2013). What are the associations between parenting, callousunemotional traits, and antisocial behavior in youth? A systematic review of evidence. Clinical Psychology Review, 33, 593-608. doi: 10.1016/j.cpr.2013.03.001

Winnicott, D.W. (1965). The maturational processes and the facilitating environment: Studies in the theory of emotional development. London, UK: Hogarth Press.

Yakeley, J., \& Adshead, G. (2013). Locks, keys, and security of mind: Psychodynamic approaches to forensic psychiatry. Journal of the American Academy of Psychiatry and the Law, 41(1), 38-45 